\title{
The DNA Damage-Induced Cell Cycle Checkpoints*
}

\author{
PIOTR WIDLAK ${ }^{\dagger}$ \\ Department of Experimental and Clinical, Radiobiology, Center of Oncology Maria, Sklodowska-Curie Memorial Institute, Gliwice \\ 44-100, Poland
}

(Received 22 November 1998; In final form 28 April 1999)

\begin{abstract}
The proliferation of eukaryotic cells is driven by a process called the cell cycle. Proper regulation of this process, leading to orderly execution of sequential steps within the cycle, ensures normal development and homeostasis of the organism. On the other hand, perturbations of the cell cycle are frequently attributed to cancer cells. Mechanisms that ensure the order and fidelity of events in the cell cycle are called checkpoints. The checkpoints induced by damaged DNA delay the cell cycle progression, providing more time for repair of lesion before DNA replication and segregation. The DNA damageinduced checkpoints can be recognized as signal transduction pathways that communicate information between DNA lesion and components of the cell cycle. Proteins involved in the cell cycle, as well as components of the signal transduction pathways communicating with the cell cycle, are frequently products of oncogenes and tumor suppressor genes. Malfunction of these genes plays a critical role in the development of human cancers. The key component in the checkpoint machinery is tumor suppressor gene p53, involved in either regulation of the cell cycle progression (e.g. G1 arrest of cells treated with DNA damaging factor) or activation of programmed cell death (apoptosis). It is postulated that p53 protein is activated by DNA damage detectors. One of the candidates for this role is DNA-dependent protein kinase (DNA-PK) which recognizes DNA strand breaks and phosphorylates $\mathrm{p} 53$ protein.
\end{abstract}

Keywords: cell cycle, checkpoints, DNA damage, DNA repair

\section{THE CELL CYCLE IS DRIVEN BY CYCLIN-DEPENDENT PROTEIN KINASES}

The act of cell division is the cumulation of series of events that have occurred since the last time cell divided. The period between two mitotic divisions defined the cell cycle. The period of actual mitosis is called M-phase. The time between mitoses is called interphase, and can be subsequently divided into G1-phase, S-phase (when DNA has to replicate) and G2-phase. In cycling somatic animal cells the cycle is repeated every $18-24$ hours. Some cells do not divide, such a non-cycling state is called G0. Commitment to chromosome replication occurs in $\mathrm{Gl}$ (so called restriction point), while to mitotic division at the end of $\mathrm{G} 2$-phase. Mechanisms regulating the

\footnotetext{
*The paper was supported by the State Committee for Scientific Research (KBN, grant 8T11E03315).

†Corresponding Author: Fax: 4832 231 3512; E-mail: widlak@onko1.instonko.gliwice.pl
} 
cell cycle have to ensure that: (i) having begun replication of DNA a cell must complete it, and (ii) a cell must not divide until replication has been completed. Loss of these features results in chromosomal aberrations that could lead to cell death or cancer development.

This is only one decade when we started to understand molecular mechanisms of the cell cycle regulation. The most prominent regulators of the cell cycle are the cyclin-dependent kinases (CDKs). CDKs are serine/threonine-specific protein kinases, able to phosphorylate many nuclear and cytoplasmic substrates. Mammalian cells have distinct CDKs, at least four of them ( $\mathrm{Cdc} 2, \mathrm{Cdk} 2, \mathrm{Cdk} 4, \mathrm{Cdk} 6)$ are directly involved in the cell cycle regulation. The activity of CDKs can be regulated by a specific phosphorylation/dephosphorylation and binding of proteins which act as positive or negative regulators. Positive regulators of CDKs are cyclins, proteins accumulating during the cell cycle progression and subsequently destroyed by proteolysis. Eight different cyclins are now known. CDKs and cyclins form specific complexes in different phases of the cycle. Cyclins D associated with Cdk4 or Cdk6, and cyclin $E$ associated with $\mathrm{Cdk} 2$ are regulators at the G1/S transition. The complex of $\mathrm{Cdk} 2$ and cyclin $\mathrm{A}$ is necessary for $S$-phase progression. The master regulator at the G2/M transition is $\mathrm{Cdc} 2$ associated with cyclin $\mathrm{B}$ (mitosis promoting factor - MPF). The complex of $\mathrm{Cdk} 7 / \mathrm{cyclin} \mathrm{H}$ phosphorylates and activates other CDKs (CDK activating kinase - CAK). During G2-phase CAK phosphorylates Cdc2 at threonine161 and Wee1/Mik1 related kinases phosphorylate $\mathrm{Cdc} 2$ at tyrosine-15 (or threonine-14). Last step of MPF activation is dephosphorylation of tyrosine15 (or threonine-14) by protein phosphatase Cdc25. Negative regulators of CDKs are protein inhibitors like $\mathrm{p} 21^{\mathrm{WAF} 1 / \mathrm{ClP} 1}, \mathrm{p} 27^{\mathrm{KIP} 1}$ or $\mathrm{p} 16^{\mathrm{INK} 4}$ (the last one is specific for cyclin D-dependent CDKs) [rev. in: Hunter \& Pines, 1994: Morgan, 1995].

$\mathrm{pRB}$ protein, the product of the retinoblastoma tumor suppressor gene, acts as a major signal transducer connecting the cell cycle with the transcriptional machinery, Hypophosphorylated pRB sequesters $\mathrm{E} 2 \mathrm{~F}$ transcription factor in a complex.
When $\mathrm{pRB}$ is hyperphosphorylated by G1-specific CDKs, it is released from the complex and E2F can activate transcription of genes necessary in $S$ phase (among them are DNA polymerases or S-phase cyclins) [rev. in: Weinberg, 1995]. More recently it was found that hypophosphorylated pRB associates with histone deacetylase HDAC1, which can modulate chromatin structure and inactivate transcription. That gave additional ability of $\mathrm{pRB}$ to repress transcription of E2F-dependent genes [Brehm et al., 1998]. Likewise pRB, many other components of the cell cycle are products of oncogenes (e.g. cyclins) or tumor suppressor genes (e.g. CDK inhibitors) [rev. in: Hunter \& Pines, 1994).

\section{DNA LESION INDUCES ARREST OF THE CELL CYCLE}

The genomes of all organisms are prone to physical and chemical assaults coming from the environment. Some genotoxic agents can induce modification or loss of bases. Among them are alkylating agents or UV radiation. Others, like ionizing radiation, lead to formation of breaks in phosphodiester backbone of DNA as well. All of these lesions are particularly dangerous for proliferating cells. Lesion formed in G1-phase can be removed without genotoxic effects if repaired before a cell enters S-phase. When damaged DNA serves as a template for synthesis of complementary strand (i.e. lesion has not been removed before S-phase entrance, or DNA has been damaged during $S$-phase progression), the presence of a lesion can affect base substitution or block DNA synthesis leaving gap in daughter DNA. Replicative gaps may be filled by postreplicative repair pathways (some of them are errorprone) or (if unrepaired) converted subsequently to a double-strand breaks (DSB). Mitotic segregation of DNA that contains DSB leads to gross chromosomal instability (chromosome rearrangement, loss or gain) [Kaufman \& Paules, 1996]. Organisms have evolved different mechanisms to repair damaged DNA. Modified bases are usually repaired in excision repair pathways. Broken DNA ends are 
repaired in recombination-based mechanisms [rev. in: Wood, 1996].

A number of mechanisms exist in a cell that interrupt the cell cycle progression when damage to the genome or mitotic spindle is detected. Such mechanisms, called checkpoints, provide fidelity of a cell replication and division. Some checkpoints control mitotic spindle within $\mathrm{M}$-phase. The other one can be activated by DNA damage in different phases of the cell cycle [Paulovich et al., 1997; Nurse, 1997]. Cell cycle checkpoints are sometimes considered as integral components of a DNA repair machinery. In fact, by delaying progression through the cycle, checkpoints provide more time for repair before critical phases of DNA replication and segregation. The idea of checkpoints has been given by Hartwell and Weinert [1989]: when initiation of late event of the cell cycle is dependent on the completion of early event, that dependence is due to a checkpoint control if a loss-of-function mutation can be found that relieves this dependence. The first known gene responsible for DNA-damage checkpoint was RAD9 gene in yeast Saccharomyces cerevisiae, which product was responsible for G2 arrest of cells containing DNA breaks [Weinert
\& Hartwell, 1988]. At the present it is known, that $\operatorname{Rad} 9$ protein is phosphorylated in response to DNA damage (probably with MEC1/TEL1 related kinases) and interacts with Rad53 protein kinase. Subsequently, kinase Rad53 activates DNA damage inducible genes and induces the cell cycle arrest [Walworth, 1998; Sun et al., 1998].

In mammalian cells mutations in p53, ATM and WAF1/CIP1 genes abrogate the G1 checkpoint. p53 protein is a transcription factor activated by DNA damage, while $\mathrm{p} 21^{\mathrm{WAF} 1 / \mathrm{CIP} 1}$ is a CDK inhibitor which transcription is dependent on p53. ATM (ataxia telangiectasia mutated) is a protein kinase, however its role in the cell cycle regulation remains unclear. p21 protein binds to and inhibits CDKs. Although p21 is relatively non-specific CDK inhibitor, its effects are particularly visible upon G1 phase. Inhibition of G1-specific CDKs with p21 prevents phosphorylation of $\mathrm{pRB}$ and activation of E2F dependent genes (Figure 1). p21 can also bind to PCNA protein, which is component of DNA polymerase $\delta$ complex, and inhibits progression of S-phase (but not repair DNA synthesis) [Pines, 1994]. p53 protein activates transcription of other DNA damage-induced gene GADD45. Likewise

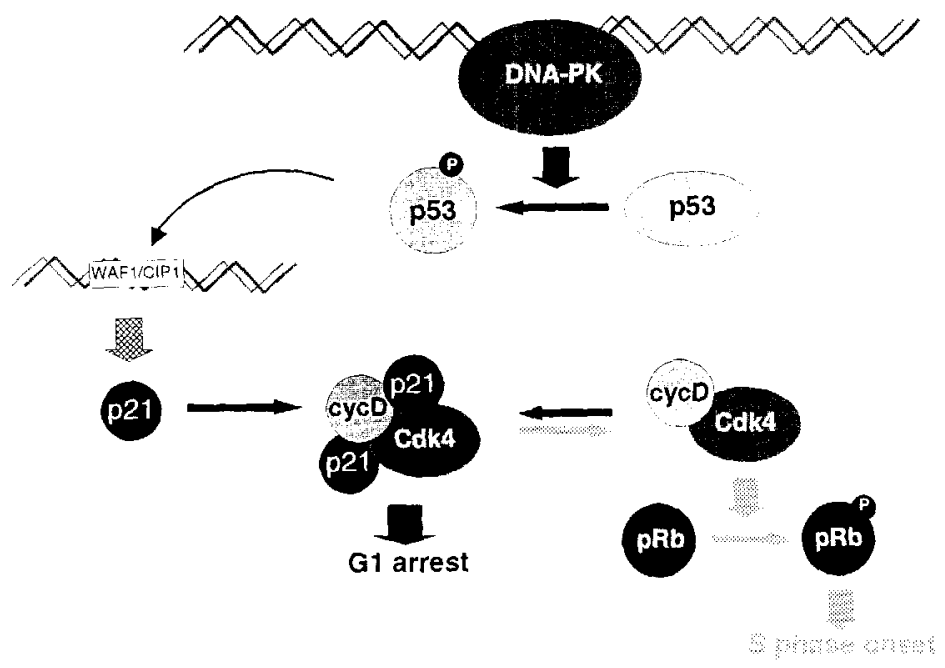

FIGURE 1 The mechanism of DNA damage-induced GI arrest of the cell cycle. Black arrows show pathways leading to delay of the cycle, gray arrows show pathways leading to progression of the cycle. Kinked double line represents DNA. Ovals represent different proteins. DNA-PK and Cdk4 are protein kinases (black circle with P denotes phosphate group). Cross-hatched arrow denotes transcription of the 21 WAF1/CIP1. 


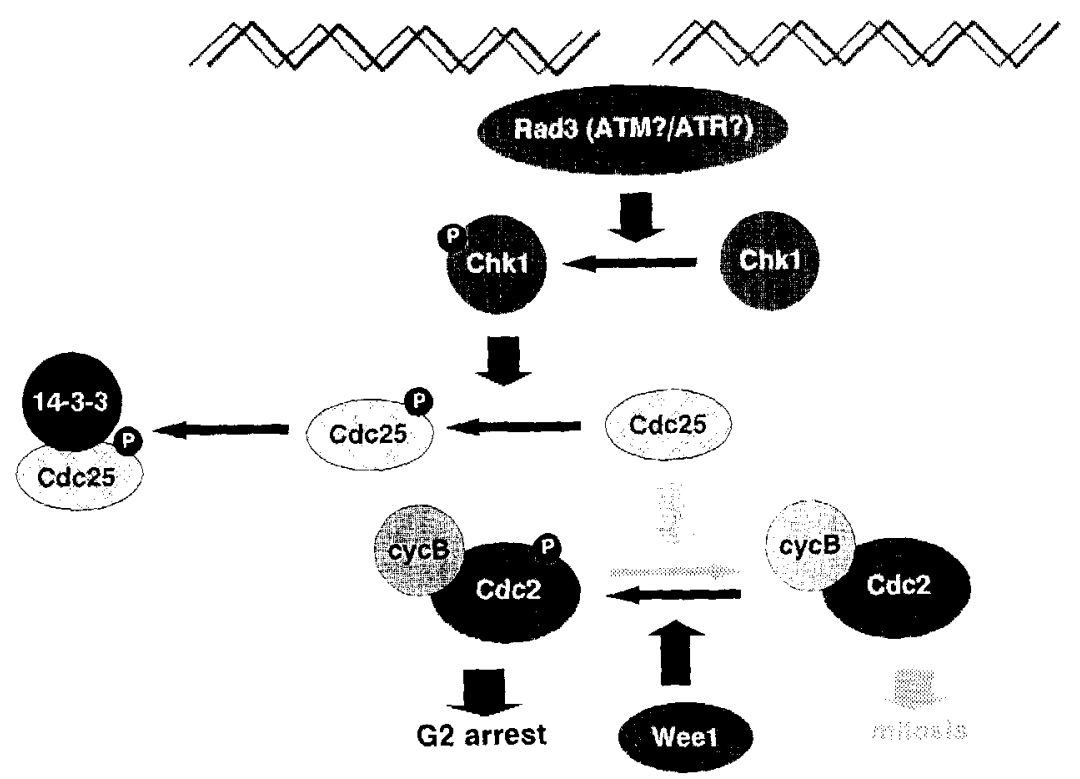

FIGURE 2 The mechanism of DNA damage-induced G2 arrest of the cell cycle. Rad3, Chk1, Weel and Cde2 are protein kinases. $\mathrm{Cdc} 25$ is a protein phosphatase. Other descriptions as at Figure 1 .

p21, Gadd45 also binds to PCNA and inhibits Sphase progression. It was also reported that Gadd45 stimulated DNA repair [Smith et al., 1994].

The mechanism of DNA damage-induced G2 checkpoint is shown on Figure 2. The model bases on data collected in mammalian cells and yeast Schizosaccharomyces pombe, however proteins involved in this pathways in different cell types are highly conserved [Weinert, 1997]. A DNA damage activates yeast protein kinase Rad3, but the mechanism of the activation is not known thus far. Human homolog of Rad3 are ATM and ATR kinases. Active Rad3 then activates the protein kinase $\mathrm{Chk} 1$ (Rad3 probably phosphorylates Chk1) [Walworth \& Bernards, 1996]. Chk1 binds to and phosphorylates protein phosphatase $\mathrm{Cdc} 25$ (on serine-216). This phosphorylation creates a binding site for 14-3-3 protein and inhibits function of the phosphatase ( $\mathrm{Cdc} 25$ is sequestered in cytoplasm in the complex with 14-3-3 protein). In a cycling cell cyclindependent kinase $\mathrm{Cdc} 2$ is phosphorylated with CAK and Weel kinases, then dephosphorylated with Cdc25 during G2 phase (see above). Inactivation of $\mathrm{Cdc} 25$ in response to DNA damage prevents the last step of MPF activation and mitotic entry [Furnari et al., 1997; Sanchez et al., 1997; Peng et al., 1997].

Additional DNA damage checkpoints prevent progression through S-phase. Among proteins involved in this pathway in mammalian cells is $\mathrm{p} 21^{\mathrm{WAF} 1 / \mathrm{ClP} 1}$ (see above). Genetic and biochemical data show that in yeast Schizosaccharomyces pombe proteins Chk1 and Cds1 (Rad53-related protein kinase which phosphorylates and activates WeeI and Mik1) are involved in the replication checkpoint [Boddy et al., 1998].

\section{P53 IS A STRESS-RESPONSE INTEGRATOR}

Since initial observations that $\mathrm{p} 53$ protein participates in the cellular response to DNA damage [Maltzman \& Czyzyk, 1984; Kastan et al,, 1991], a bulk of data has accumulated showing that p53 is the most important player in DNA damage-induced checkpoint in humans. 553 protein is a transcription factor consisting of four functional domains: transcriptional activation domain (which bind to components of RNA polymerase II 
complex), sequence-specific DNA binding domain (binding to DNA motif which is present in p53activated genes), oligomerization domain and $\mathrm{C}$ terminal domain which is responsible for binding to DNA ends or gaps. In normal situation p53 is very unstable protein, with half-life of about 20 minutes. In cells treated with DNA-damaging factors p53 is stabilized and accumulated. Different mechanisms have been postulated to activate p53. Among them are: phosphorylation (by different kinases), translocation from cytoplasm to nucleus, formation of dimers or tetramers, formation of complexes with other proteins, binding to DNA strand breaks or gaps. The cis-acting, p53-responsive element has been found in couple of genes, which are regarded as p53-activated. Among them are previously mentioned GADD45, WAF1/CIP1 and 14-3-3 $\sigma$ genes, involved in the cell cycle regulation. Two other genes regulated by $\mathrm{p} 53, \mathrm{BAX}$ and $\mathrm{IGF}-\mathrm{BP} 3$, are involved in activation of apoptosis, which is the other way that cells can respond to DNA damage. p53 protein activates also $m d m 2$ oncogene, which product binds to and inactivates p53 [rev: Cox \& Lane, 1995; Levine, 1997]

p53 protein binds to many other nuclear proteins. $\mathrm{N}$-terminal domain of p53 binds to component of basal transcription factor TFIID (TBP and TAF's), their binding activates p53-specific genes. On the other hand, it was suggested that binding of TBP represses transcription of genes which don't have p53-responsive element. Transcriptional activation function of $\mathrm{p} 53$ is modulated by other proteins. Binding of couple viral proteins (e.g. SV40 T antigen) and oncoprotein MDM2 inhibits p53 activity and promotes its degradation. Binding of other nuclear proteins (e.g. oncoprotein $\mathrm{c}-\mathrm{Abl}$ or protein p33 ${ }^{\mathrm{ING1}}$ ) positively stimulates p53 activity. Protein p53 can also bind helicases XPD and XPB, components of TFIIH basal transcription factor involved in the nucleotide excision repair pathway (suggesting that p53 plays a role in direct modulating of DNA repair). As one can see, all the ways by which mammalian cell respond to injury (block of the cell cycle, inhibition of DNA replication and transcription, activation of repair or eventually undergoing apoptosis) are regulated by p53 (see Figure 3) [rev. in: Cox \& Lane, 1995; Hansen \& Oren, 1997; Levine, 1997].

At the moment, it is generally accepted that under environmental stress cells accumulate and activate protein $\mathrm{p} 53$. The best known factor that activates p53 is DNA damage. However, the signaling pathways connecting DNA damage with

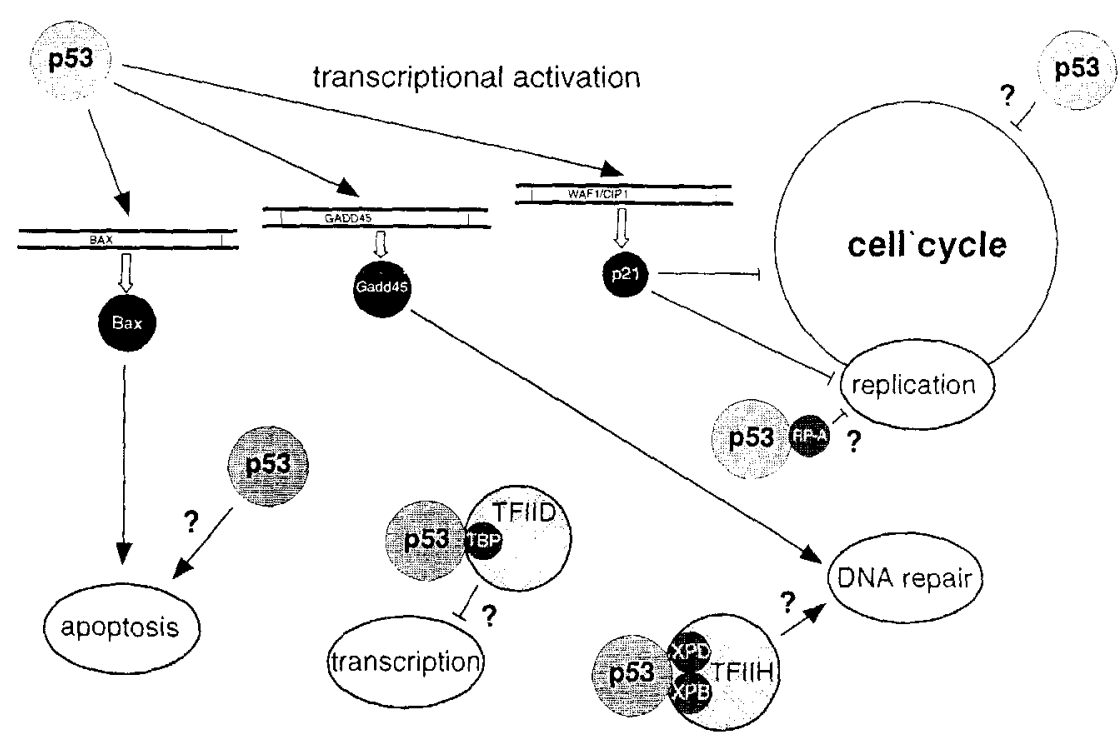

FIGURE 3 The scheme of p53-dependent pathways. Empty ovals represent different cellular pathways regulated by protein p53. Empty arrows denote transcription of p53-dependent genes. Arrows and blunted-arrows represent activation and inactivation of different processes. Possible effects are described with question marks. Shown are complexes of p53 with other proteins. 
modification and activation of p53 are not clear thus far. One of the proteins that are postulated to be a DNA damage sensor which activates p53 is DNA-dependent protein kinase (DNA-PK). DNAPK, together with ATM and ATR, belongs to family of PIK-related (phosphatidylinositol kinase) protein kinases. DNA-PK is a trimeric protein consisting of catalytic subunit DNA-PK $\mathrm{CS}_{\mathrm{C}}$ and DNA-binding heterodimer $\mathrm{Ku} 70 / \mathrm{Ku} 86$. The protein is activated when binds to DNA double strand ends. DNA-PK is known to be involved in VDJ recombination of immunoglobulin genes in lymphocytes and in repair of DNA double strand breaks. Among proteins phosphorylated with DNA-PK (at serine residues) are transcription factors, chromatin proteins and DNA-PK itself [Anderson \& Lees-Miller, 1992; Gottlieb \& Jackson, 1993]. In human cells which were $\gamma$-irradiated DNA-PK can phosphorylate p53 protein at serines- 15 and -37 . This phosphorylation of p53 impairs the ability of MDM2 to inhibit p53-dependent transactivation (it is probably due to phosphorylation-induced conformational changes that prevent binding of MDM2) [Shieh et al., 1997]. In addition, DNA-PK can phosphorylate oncoprotein c-Abl [Kharbanda et al., 1997] which activates p53. It is known, that in some situations activation of $p 53$ doesn't depend on DNA-PK. The phosphorylation of p53 at serine-15 in cells with mutated catalytic subunit of DNA-PK (scid cells) suggests that p53 can be phosphorylated by other kinases that possesses similar specificity (ATM?). On the other hand, UV-irradiation of cells activates p53 via phosphorylation at residues different than specific for DNA-PK [Kapoor \& Lozano, 1998].

An important regulatory problem is how to escape from DNA damage-induced arrest and restart the cell cycle when damage is repaired. In mammalian cell, the mechanism of such an escape depends on MDM2 protein and its ability to inactivate p53. p53 protein activates transcription of MDM2, which in turn binds to p53. Binding of MDM2 inactivates [Chen et al., 1994] and promotes a rapid proteolytic degradation of p53 [Haupt et al., 1997]. In this meaning MDM2 protein is a component of a negative feedback control of $\mathrm{p} 53$. Overexpression of MDM2 in some tumor cells results in permanent inactivation of $\mathrm{p} 53$. The product of another tumor suppressor gene, protein $\mathrm{p} 19^{\mathrm{ARF}}$, can bind to MDM2 and promote its degradation (preventing inhibition of p53) [Zhang et al. 1998; Pomerantz et al., 1998]. In yeast Saccharomyces cerevisiae a mechanism of an escape from the DNA damageinduced cell cycle arrest depends on CDC5 gene. The mechanism allows to override the checkpoint even if DNA damage cannot be repaired (so called adaptation) [Toczyski et al., 1997]. Presumably, a metazoan cell which failed to repair DNA damage would rather trigger a programmed cell death (apoptosis) pathway, while a checkpoint adaptation can be involved in cancer development.

The bulk of data that have accumulated over past decade show that p53 is a central element of a cellular response to stress. Upstream of p53 act different (yet not fully identified) sensors. Downstream of p53 act much better known effectors. Some of them activate the cell cycle checkpoint and DNA repair, enhancing cell survival. Others activate death by apoptosis, that is alternative way to eliminate damage (yet together with cell). Any malfunction of p53 will affect the maintenance of genome integrity and increase the probability of disease. In fact more than $50 \%$ of human cancers contain mutations in p53 gene (most of them are point mutations which inactivate $\mathrm{p} 53$ as a transcription factor). On the other hand, one should keep in mind other genes and proteins involved in the cell cycle regulation. All of them are important for normal growth and development, while mutation or loss any of them can account for increased risk of tumor disease.

\section{REFERENCES}

Anderson, C. W. and Lees-Miller, S. P. (1992). The nuclear serine/threonine protein kinase DNA-PK. Crit. Rev. Eukary. Gene Expr., 2, 283-314.

Boddy, M. N., Furnari, B., Mondesert, O. and Russell, P. (1998). Replication checkpoint enforced by kinases Cds 1 and Chk1. Science, 280, 909-912.

Brehm, A., Miska, E. A., Mccance, D. J., Reid, J. L., Bannister, A. J. and Kouzarides, T. (1998). Retinoblastoma protein recruits histone deacetylase to repress transcription. Nature, 391, 597-601. 
Chen, C.-Y., Oliner, J. D., Zhan, Q., Fornace, A. J., Vogelstein, B. and Kastan, M. B. (1994). Interactions between $\mathrm{p} 53$ and MDM2 in a mammalian cell cycle checkpoint pathway. Proc, Natl. Acad. Sci. USA, 91, 2684-2688.

Cox, L. S. and Lane, D. P. (1995). Tumor suppressors, kinases and clamps: how p53 regulates the cell cycle response to DNA damage. BioEssays, 17, 501-508.

Furnari, B., Rhind, N. and Russell, P. (1997). Cdc25 mitotic inducer targeted by Chk1 DNA damage checkpoint kinase. Science, 277, 1495-1497.

Gottlieb, T. M. and Jackson, S. P. (1993). The DNA-dependent protein kinase: requirement for DNA ends and association with $\mathrm{Ku}$ antigen. Cell, 72, 131-142.

Hansen, R. and Oren, M. (1997). p53; from inductive signal to cellular effect. Curr. Opin. Gen. Dev., 7, 46-51.

Hartwell, L. H. and Weinert, T. A. (1989). Checkpoints: controls that ensure the order of cell cycle events. Science, 246, 629-634.

Haupt, Y., Maya, R., Kazaz, A. and Oren, M. (1997). Mdm2 promotes the rapid degradation of p53. Nature, 387, 296-299.

Hunter, T. and Pines, J. (1994). Cyclins and cancer: cyclin D and CDK inhibitors come of age. Cell, 79, 573-582.

Kapoor, M. and Lozano, G. (1998). Functional activation of p53 via phosphorylation following DNA damage by UV but not gamma radiation. Proc. Natl. Acad. Sci. USA, 95, 2834-2837.

Kastan, M. B., Onyekwere, O., Sidransky, D., Vogelstein, B. and CRAIG, R. W. (1991). Participation of p53 protein in the celJular response to DNA damage. Cancer Res, 51, 6304-6311.

Kaufmann, W. K. and Paules, R. S. (1996). DNA damage and cell cycle checkpoints. FASEB J., 10, 238-247.

Kharbanda, S., Pandey, P., Jin, S., Inoue, S., Bharti, A., Yuan, Z.-M., Weichselbaum, R., Weaver, D. and Kufe, D. (1997). Functional interaction between $D N A-P K$ and $c-A b l$ in response to DNA damage. Nature, 386, 732-735.

Levine, A. J. (1997). p53, the cellular gatekeeper for growth and division. Cell, 88, 323-331.

Maltzman, W. and Czyzyk, L. (1984). UV irradiation stimulates levels of $\mathrm{p} 53$ cellular tumor antigen in nontransformed mouse cells. Mol. Cel. Biol., 4, 1689-1694.

Morgan, D. O. (1995). Principles of CDK regulation. Nature, 374, $131-134$.

Nurse, P. (1997). Checkpoint pathways come of age. Cell, 91 , $865-867$.

Paulovich, A. G., Toczyski, D. P. and Hartwell, L. H. (1997). When checkpoints fail. Cell, 88, 315-321.

Peng, C.-Y., Graves, P. R., Thoma, R. S., Wu, Z., Shaw, A. S. and Piwnica-Worms, H. (1997). Mitotic and G2 checkpoint control: regulation of 14-3-3 protein binding by phosphorylation of Cdc25C on serine-216. Science, 277, 1501-1504.

Pines, J. (1994). p21 inhibits cyclin shock. Nature, 369, 520-521.

Pomerantz, J., Schreiber-Agus, N., Liegeois, N. J., Silverman, A., Alland, L., Chin, L., Potes, J., Chen, K., Orlow, I., Lee, H.-W., Cordon-cardo, C. and Depinho, R. A. (1998). The Ink4a tumor suppressor gene product, p19 Arf , interacts with MDM and neutralizes MDM2's inhibition of p53. Cell, 92. $713-723$.

Sanchez, Y., Wong, C., Thoma, R. S., Richman, R., Wu, Z., Piwnica-Worms, H. and Elledge, S. J. (1997). Conservation of the Chk1 checkpoint pathway in mammals: linkage of DNA damage to Cdk regulation through $\mathrm{Cdc25}$. Science, 277. 1497-1501.

Shieh, S.-Y., Ikeda, M., Taya, Y. and Prives, C. (1997). DNA damage-induced phosphorylation of p53 alleviates inhibition by MDM2. Cell, 91, 325-334.

Smith, M. L., Chen, I.-T., Zhan, Q., Bae, I., Chen, C.-Y., Gilmer, T. M., Kastan, M. B., O'Connor, P. M. and Fornace, A. J. (1994). Interaction of the p53-regulated protein Gadd45 with proliferating cell nuclear antigen. Science, 266, 1376-1380.

Sun, Z., Hsiao, J., Fay, D. S. and Stern, D. F. (1998). Rad FHA domain associated with phosphorylated Rad9 in the DNA damage checkpoint. Science, 281, 272-274.

Toczyski, D. P., Gaigoczy, D. J. and Hartwell, L. H. (1997). CDC5 and CKII control adaptation to the yeast DNA damage checkpoint. Cell, 90, 1097-1106.

Walworth, N. C. and Bernards, R. (1996). Rad-dependent responses of the chk1-encoded protein kinase at the DNA damage checkpoint. Science, 271, 353-356.

Walworth, N. C. (1998). Rad9 comes of age. Science, 281, $185-186$

Weinberg, R. A. (1995). The retinoblastoma protein and cell cycle control. Cell, 81, 323-330.

Weinert, T. A. and Hartwell, L. H. (1988). The RAD9 gene controls the cell cycle response to DNA damage in Saccharomyces cerevisiae. Science, 241, 317-322.

Weinert, T. (1997). A DNA damage checkpoint meets the cell cycle engine. Science, 277, 1450-1451.

Wood, R. D. (1996). DNA repair in eukaryotes. Annu. Rev. Biochem., 65, 136-167.

Zhang, Y., Xiong, Y. and Yarbrough, W. G. (1998). ARF promotes MDM2 degradation and stabilizes p53: ARF-INK4a locus deletion impairs both the $\mathrm{Rb}$ and $\mathrm{p} 53$ tumor suppression pathways. Cell, $92725-734$. 


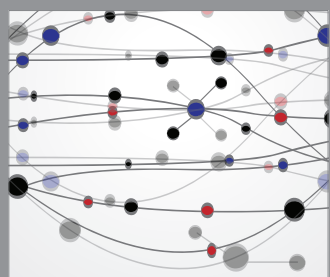

The Scientific World Journal
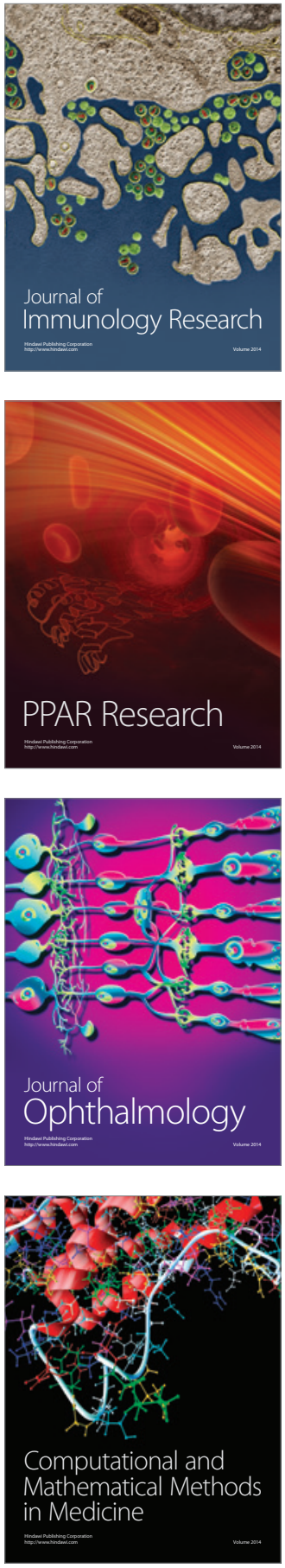

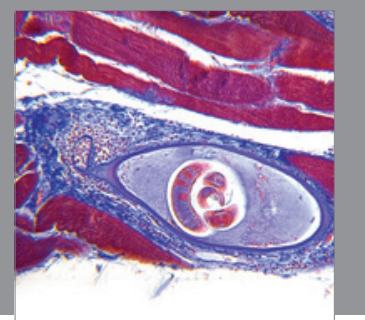

Gastroenterology

Research and Practice
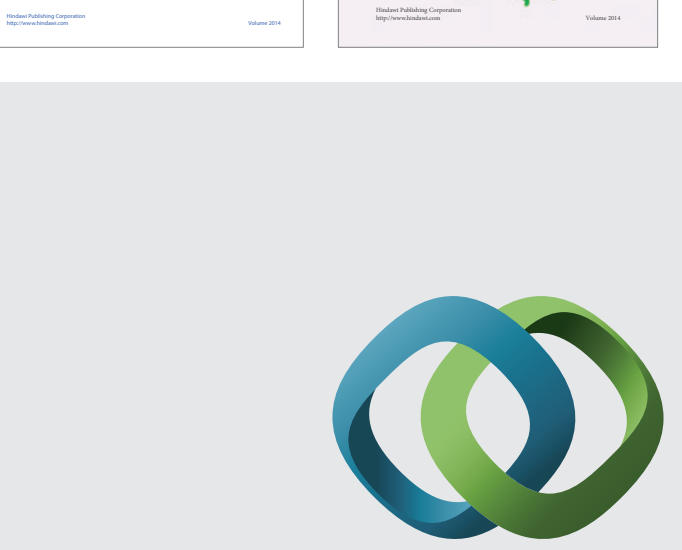

\section{Hindawi}

Submit your manuscripts at

http://www.hindawi.com
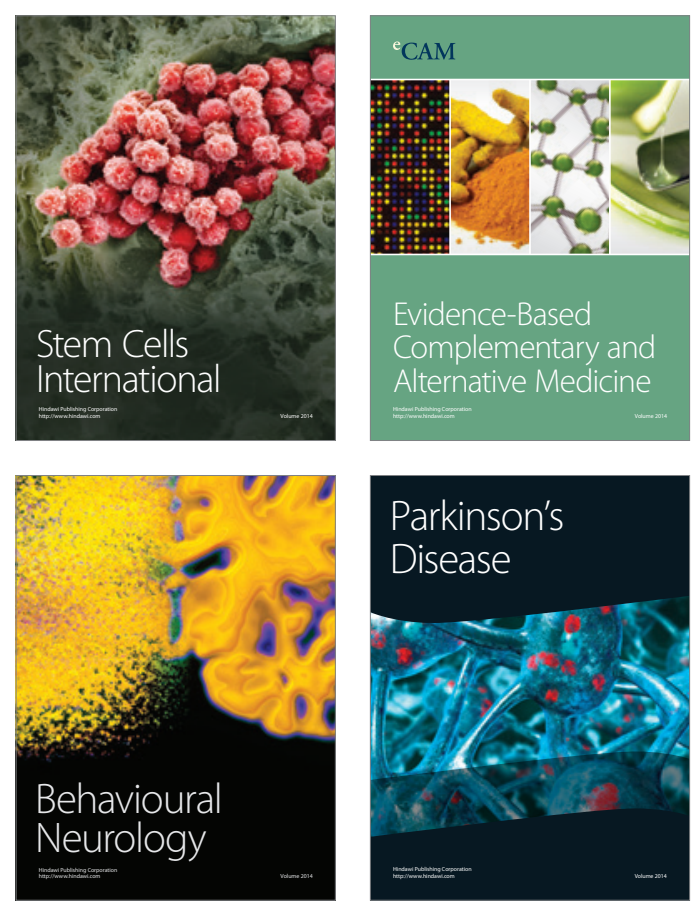

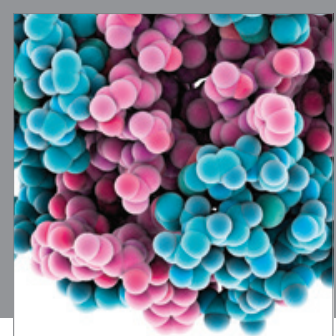

Journal of
Diabetes Research

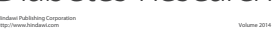

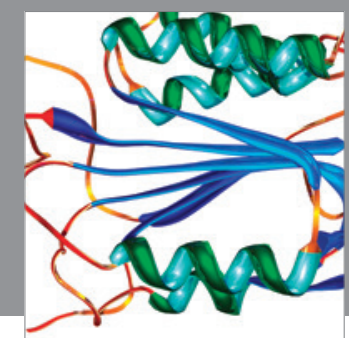

Disease Markers
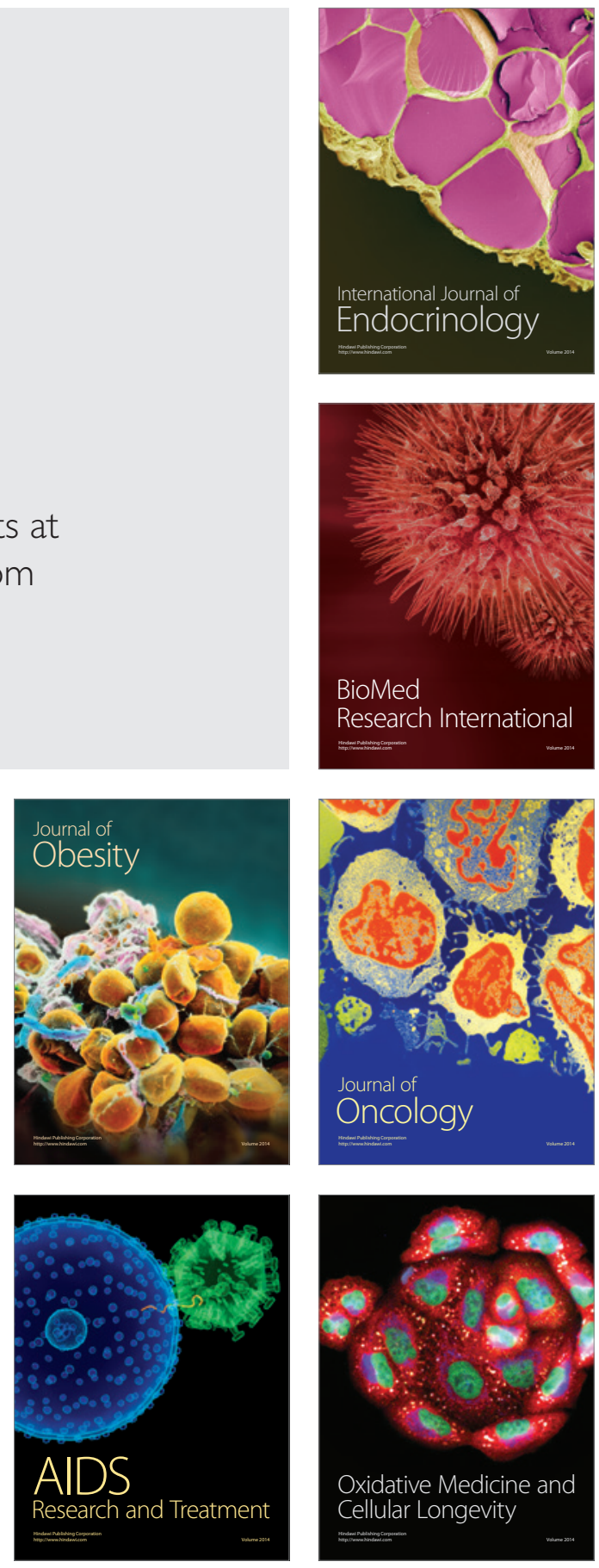